
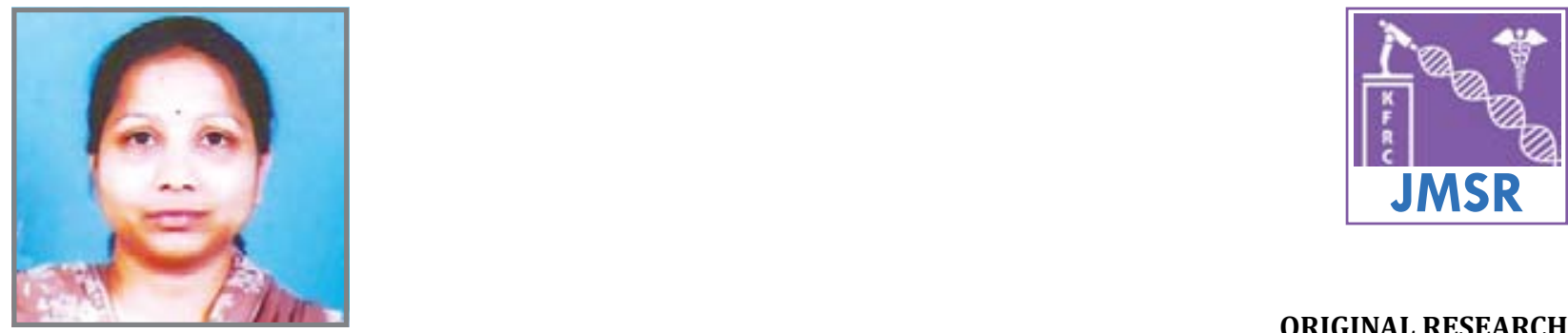

Dr. Sukrutha Gopal Reddy

ORIGINAL RESEARCH

\title{
Seroprevalence of transfusion transmissible infections among healthy blood donors at KIMS blood bank
}

\author{
Dr. Sukrutha Gopal Reddy ${ }^{1,}{ }^{*}$, Dr. D. Radhika Chowdary ${ }^{1}$ and Dr. Anil Kumar Bilolikar ${ }^{1}$ \\ ${ }^{1}$ Department of Blood Bank \& Laboratory Services, Krishna Institute of Medical Sciences, \\ Minister Road, Secunderabad - 500003, Telangana, India
}

\begin{abstract}
Background: Safe blood is a critical component in improving health care and in preventing the spread of infectious diseases.

Aims \& Objectives: Blood transfusion can cause the transmission of infectious to recipients. This is an important mode of infection. The aim of the study was to assess the prevalence of such type of infection among blood donors and to compare the seroprevalence of transfusion transmitted diseases in blood donors. Retrospective study was conducted for 5 years from January-2009 to December-2013 at KIMS Blood Bank, Secunderabad, India.

Materials and methods: All donors reporting to the blood bank during the period January-2009 to December2013 were screened for human immunodeficiency virus (HIV) $1 \& 2$, hepatitis C viruses, malaria and syphilis. Screening of HIV, hepatitis B and hepatitis C viruses were done by chemillumiencies and syphilis was screened by RPR method.

Results: A total of 39780 voluntary blood donors were screened, of which 38697 were males and 1083 were females. Seropositivity of HIV, hepatitis B, hepatitis C viruses \& syphilis were $0.26 \%, 1.28 \%, 0.51 \%$ and $0.03 \%$ respectively. No blood donors test showed positivity for malaria parasite.
\end{abstract}

Conclusion: With the implementation of strict donor selection criteria and use of sensitive screening test, it may be possible to reduce the incidence of TTIs.

Keywords: Human immunodeficiency virus; Hepatitis B virus; Hepatitis C virus; Seroprevalence; Transfusion transmitted infections

*Corresponding author: Dr. Sukrutha Gopal Reddy, Department of Blood Bank \& Laboratory Services, Krishna Institute of Medical Sciences, Minister Road, Secunderabad - 500003, Telangana, India. Email: sukruthagopalreddy@gmail.com

Received 10 April 2014; Revised 22 May 2014; Accepted 11 June 2014

Citation: Sukrutha Gopal R, Radhika Chowdary D, Anil Kumar B (2014) Seroprevalence of transfusion transmissible infections among healthy blood donors at KIMS blood bank. J Med Sci Res 2(3):137-139. DOI: http://dx.doi.org/10.17727/JMSR.2014/2024

Copyright: (C) 2014 KIMS Foundation and Research Centre. All Rights Reserved.

\section{Introduction}

Blood transfusion, an integral part of medicine and surgery, also carries the risk of transfusiontransmissible infections like hepatitis B, hepatitis C, human immunodeficiency virus (HIV) $1 \& 2$, syphilis, malaria and infrequently toxoplasmosis, brucellosis \& viral infections like cytomegalovirus (CMV), Epstein-Barr virus (EBV) and herpes [1] measuring their severity. World Health Organization (WHO) has recommended pre-transfusion blood test for HIV, hepatitis B (HBV), hepatitis C viruses (HCV), syphilis and malaria as mandatory [1]. All these diseases are capable of causing significant mortality, morbidity along with a financial burden for both the affected person and the country [2]. 
Every unit of blood transfusion there is a $1 \%$ chance of transfusion related complications including transfusion transmitted infections [1]. An increase in transfusion related infection has been reported in India [3]. India is already carrying a burden of 50 million of HBV carriers and 2,027 million of HIV cases. Keeping in mind the grave consequences of these infections and to restrain the transmission to minimum, it is very important to remain vigilant about the possible spread of these diseases through blood transfusion [4].

In our study, we aimed to estimate the prevalence of HIV, HBV, HCV and syphilis among blood donors. Accurate estimates of risks of transfusion transmitted infections (TTIs) are essential for monitoring safety of blood supply. Monitoring the incidence of TTIs in blood donors is important for estimating the risk of transfusion and optimizing donor recruitment strategies to minimize transmission. This knowledge might give us the idea of disease burden of the society and the basic epidemiology of these diseases in the community.

\section{Materials and methods}

A total number of 39,780 samples of blood were collected from donors from January 2009 to December 2013 at KIMS Blood Bank, Secunderabad. Donors were selected by taking history, clinical examination and also following strict donor's selection criteria to eliminate professional donors.

Samples were screened by Chemillumiences method (Architect Plus) for HIV-1 P24 antigen and anti-HIV 1 \& 2 (4th generation ELISA), anti-HCV, and HBsAg Rapid Plasma Reagin (RPR) test kits (Carbogen, Tulip) are used for screening syphilis and parabank kits for screening malaria parasite. All reactive samples were labeled as seropositive, disinfected and discarded.

\section{Results}

In the present study, out of total 39780 blood donors, $97.2 \%$ were males and $2.73 \%$ were females, which show predominance of males as compared to females [Table 1].

The prevalence of HBs Ag, anti-HCV, VDRL, and antiHIV among voluntary blood donors in the study population were shown in [Figure 1]. The overall seroprevalence of HIV, HBV, HCV, syphilis were $0.26 \%, 1.28 \%, 0.51 \%$ and $0.03 \%$ respectively. The highest prevalence was observed for HBV followed by HCV, HIV and syphilis in decreasing order.
Table 1: Sex wise distribution of healthy donors.

\begin{tabular}{|cccc|}
\hline Year & Total Donors & Males (\%) & Female (\%) \\
\hline 2009 & 9582 & $9277(96.8 \%)$ & $305(3.18 \%)$ \\
2010 & 8163 & $7865(96.3 \%)$ & $298(3.65 \%)$ \\
2011 & 6699 & $6518(97.2 \%)$ & $181(2.70 \%)$ \\
2012 & 7302 & $7175(98.2 \%)$ & $127(1.71 \%)$ \\
2013 & 8034 & $7862(97.8 \%)$ & $172(2.14 \%)$ \\
Total & 39780 & $38697(97.27 \%)$ & $1083(2.73 \%)$ \\
\hline
\end{tabular}

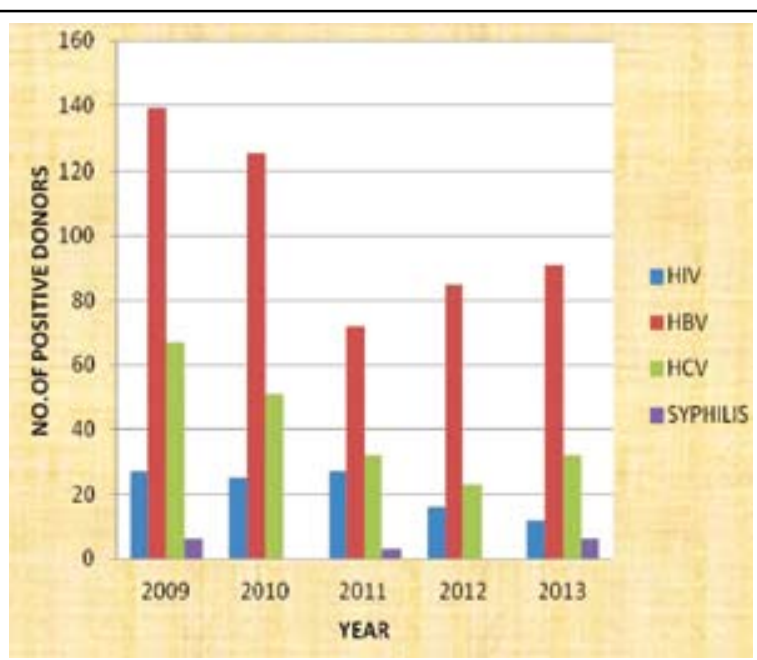

Figure 1: Overall seropositivity and trends of HIV, HBV, HCV and syphilis.

\section{Discussion}

Blood and blood products are an integral and life saving procedures of modern medicine, but simultaneously it carries the risk of transmitting the life threatening transmissible infectious [2]. Screening of blood is now mandatory for many diseases and it is undertaken routinely in blood banks. Transmission of TTIs during the serologically window period still poses a threat to blood safety in environments where there is high rate of TTIs [4].

Our study seroprevalence of TTIs was as follows HIV $0.26 \%$, HBV $1.28 \%$, HCV $0.51 \%$ and syphilis $0.03 \%$. No Blood donor test showed positivity for malaria parasite. The present study revealed overall prevalence of HIV seropositivity was $0.26 \%$, which was similar to findings by Rajvir Singh et al. (0.25\%) [2], Das BK et al. (0.32\%) [5], Arora D et al. (0.3\%) [6] and Patel SV et al. (0.30\%) [7]. Variable results of $0.01 \%$ [8], $0.1 \%$ [9] and $0.64 \%$ [10] have also been reported in various other studies. 
Present study revealed seroprevalence of HBV at $1.28 \%$ was lower than that reported by other studies by Arora D et al. (1.7\%) [6], Sinha SK (2.27\%) [10], Garg S (3.44\%) [11], Nilima sawke (2.9\%) [12], whereas few studies reported lower level of prevalence Arumugam et al. (0.74\%) [8] and Luna Adhikari et al. (0.78\%) [13].

HCV infection is an evolving public health problem globally. For hepatitis C, the estimated prevalence in this study was $0.51 \%$ familiar reported by Nilima Sawke et al. (0.57\%) [12], yet another set of studies reported $1.0 \%, 0.23 \%, 0.35 \%$ by Aora D et al. [6], Pallavi et al. [14] and Das BK [5] respectively.

In this study, syphilis positivity was $0.03 \%$, which are similar with the study done by S.T. Arumugam et al. [8] i.e. $0.03 \%$ whereas other studies reported $0.25 \%, 0.35 \%, 0.9 \%, 0.62 \%$ by Sangita Patel et al. [7], Das BK et al. [5], Arora D et al. [6] and Rajvir Singh et al. [3] respectively.

\section{Conclusion}

The time and cost involved in screening donated blood can be reduced by an effective donor education and selection criteria. Blood is still one of the leading risk factor of spread of the TTIs i.e. HIV, hepatitis B, hepatitis $C$ viruses and syphilis.

\section{Conflict of interest}

The authors declare no conflict of interest.

\section{References}

1. Widmann FK, Technical manual American Associations of Blood Banks, Anglington USA: 1985, pp 325-344.

2. Rose D, Sudharsanam A, Adankatti T, Babu PG, John TJ. Increasing Prevalence of HIV antibody among blood donors monitored over 9 years in blood donors monitored over 9 years in blood banks. Indian J Med Res. 1998; 108:42-44.

3. Rajvir Singh, Prakriti Vohra, Pooja Singla, Uma Chaudhary. Seroprevalence of Transfusion transmissible infections among healthy blood donors at general hospital, Sonepat, North India. Journal of Evolution of Medical and Dental Sciences 2013; 12(26):4816-4820.

4. Giri PA, Deshpande JD, Phalke DB, Karle LB. Seroprevalence of transfusion transmissible infections among voluntary blood donors at a tertiary care teaching hospital in rural area of India. J Family Med Prim Care. 2012; 1(1):48-51. Doi: 10.4103/2249-4863.94452.

5. Das BK, Aditya S, Chakrovorty SK, Datta PK, Joseph A. Seroprevalence of Hepatitis B, Hepatitits C, and human immunodeficiency virus among healthy voluntary first-time blood donors in Kolkata. Ann Trop Med Public Health 2011; 4:86-90.
6. Arora D, Arora B, Khetarpal A. Seroprevalence of HIV, HBV, HCV and syphilis in blood donors in Southern Haryan. Indian J Pathol Microbiol. 2010; 53:308-319.

7. Patel SV, Popat CN, Mazumdar VS, Shah MB, Shringarpure K, et al. Seroprevalence of HIV, HBV, HCV and Syphilis in blood donors at a tertiary hospital (Blood Bank) in Vadodara. Int J Med Sci Public Health 2013; 2:747-750.

8. Radhiga ST, Arumugam P, Kalpana S, Natarajan MV. Patterns of Transfusion transmitted infection in past 10 years among voluntary blood donors in Chennai - A cross sectional study. IOSR Journal of Pharmacy and Biological Sciences 2012; 2(1):01-04.

9. Agarwal VK, Sharma VP, Agarwal P, Gupta D. Sero-prevalence of transfusion transmissible infections among blood onors in urban area Asian J Med Res. 2012; 1(3):112-114.

10. Sinha SK, Roychoudhary, Biswas K, Biswas P, Bandopadhyay R. Prevalence of HIV, Hepatitis B, Hepatitis C and syphilis in donor's blood: A study from eastern part of India. Open Journal of Hematology 2012; 3-1.

11. Garg S, Mathur DR, Gard DK. Comparison of seropositivity of HIV, HBV, HCV and Syphilis in replacement and voluntary blood donors in western India. India J Pathol Microbiol. 2001; 44:409-412.

12. Nilima Sawke, Sawke GK, Chawla. Seroprevalence of common transfusion - Transmitted infections among blood donors. People's journal of scientific research 2010; 3(1):5-7.

13. Luna Adhikar, Dharmaraj Bhatta. Infectious disease maker in blood donors at central referral hospital Gangtok, Sikkim. Asian J Transfusion Sciences 2010; 4(1):41-42.

14. Pallavi P, Ganesh C, Jayashree K, Manjunath G. Seroprevalence and Trends in Transfusion Transmitted Infections among Blood Donors in a University Hospital Blood Bank: A 5 Year Study. Indian J Hematol Blood Transfus. 2011; 27:1-6.

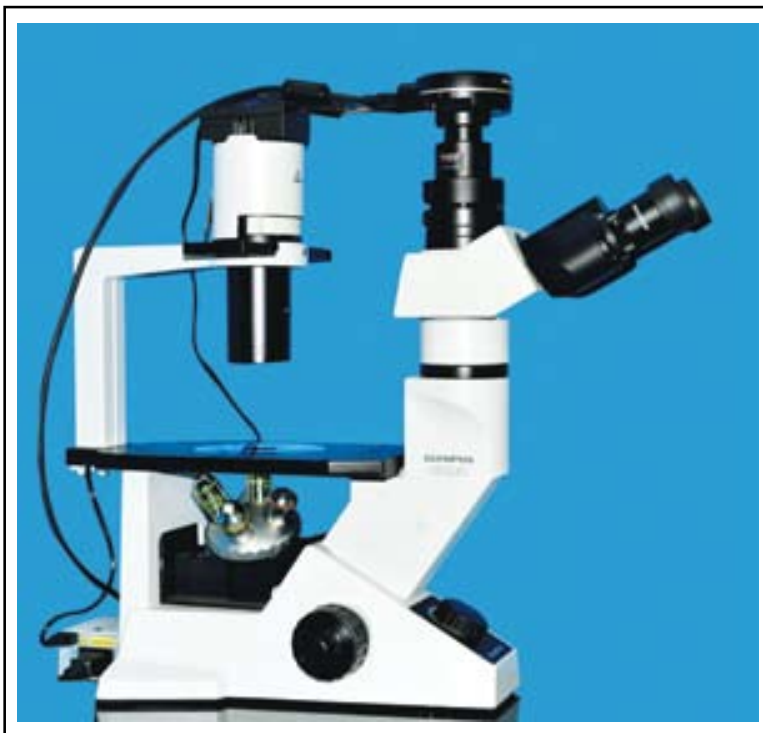

Trinocular Inverted microscope at KFRC 